\title{
Tratamento físico, químico e biológico de lixiviado de aterro sanitário e vinhaça de cana de açúcar
}

\section{Physical, chemical and biological treatment of landfill leachate and sugarcane vinasse}

\author{
Evelyne Morgana Ferreira Costa ${ }^{1 *}$, Valderi Duarte Leite ${ }^{1}$, Andreia Freitas Silva ${ }^{1}$, Gabriely \\ Dias Dantas ${ }^{1}$, André Luiz Brito Muniz ${ }^{1}$, Ingrid Lellis Ricarte Cavalcanti ${ }^{1}$
}

\section{RESUMO}

Lixiviado de aterro sanitário é um subproduto líquido advindo de infiltrações de águas pluviais e da biodegradação da fração orgânica fermentavel depositada em aterro sanitário, este apresenta elevada concentração de nitrogênio amoniacal e matéria orgânica recalcitrante. Tendo em vista a importância da busca por novas tecnologias de tratamento para o lixiviado gerado em aterros sanitários, nesta pesquisa foi avaliada a eficiência do tratamento conjugado de lixiviado de aterro sanitário e vinhaça de cana de açúcar empregando-se os processos físicos, químicos e biológicos, em um reator de dessorção seguido de reator UASB. O substrato utilizado para alimentação do reator UASB consistia da mistura de vinhaça de cana açúcar mais lixiviado de aterro sanitário em proporções que propiciasse a formação do substrato com concentração média de $\mathrm{N}_{-} \mathrm{NH}_{4}{ }^{+}$de $160 \mathrm{mg} . \mathrm{L}^{-1}$. O reator de dessorção apresentou eficiência média em termos de remoção de $\mathrm{N}-\mathrm{NH}_{4}{ }^{+}$de $88 \%$, sem necessidade de adição de substâncias químicas, tornando possível pós-tratamento do lixiviado por via biológica. A eficiência média de remoção de DQO total e $\mathrm{DQO}_{\text {solúvel }}$ no reator UASB foram de $68 \%$ e $47,6 \%$ respectivamente.

Palavras-chave: Lixiviado de aterro sanitário; Tratamento biológico; Dessorção de amônia; Vinhaça de cana de açúcar.

\section{ABSTRACT}

Landfill leachate is a liquid by-product resulting from infiltration of rainwater and from the biodegradation of the fermentable organic fraction deposited in a sanitary landfill. It has a high concentration of ammoniacal nitrogen and recalcitrant organic matter. In view of the importance of the search for new treatment technologies for the leachate generated in sanitary landfills, in this research the efficiency of the combined treatment of landfill leachate and sugarcane vinasse was evaluated using physical, chemical and biological processes. , in a desorption reactor followed by a UASB reactor. The substrate used to feed the UASB reactor consisted of a mixture of sugarcane vinasse plus leached from a landfill in proportions that favored the formation of the substrate with an average concentration of N-NH4+ of $160 \mathrm{mg} . \mathrm{L}^{-1}$. The desorption reactor showed an average efficiency in terms of N-NH4+ removal of $88 \%$, without the need to add chemical substances, making it possible to post-treatment of the leachate by biological means. The average efficiency of removal of total COD and soluble COD in the UASB reactor were $68 \%$ and $47.6 \%$, respectively.

Keywords: Landfill leachate; Biological treatment; Ammonia desorption; Sugar cane vinasse.

\footnotetext{
${ }^{1}$ Universidade Estadual da Paraíba - UEPB. *evelyne.fcosta@gmail.com
} 


\section{INTRODUÇÃO}

A disposição inadequada dos resíduos sólidos urbanos (RSU) no meio ambiente principalmente a céu aberto, pode ocasionar elevados riscos à saúde da população, além de alterar a qualidade do ar, do solo e dos recursos hídricos. De acordo com a Política Nacional de Resíduos Sólidos (PNRS), instituída pela Lei n 12.305 , de 2 de agosto de 2010, em seu Art. $3^{\circ}$, o local de disposição final ambientalmente adequado para os RSU são os aterros sanitários (BRASIL, 2010).

Entretanto, os aterros sanitários propiciam a geração de outra forma de poluição, o lixiviado, que é o subproduto líquido advindo de infiltrações pluviais e da biodegradação da fração orgânica fermentavel depositada nesses locais (NASCENTES et al., 2015). Esse subproduto apresenta elevadas concentrações de Nitrogênio Amoniacal $\left(\mathrm{N}^{-\mathrm{NH}_{4}}{ }^{+}\right)$e matéria orgânica recalcitrante, o que consequentemente torna mais difícil a adequação de técnicas eficientes e acessíveis para o seu tratamento (El-GOHARY \& KAMEL, 2016; BASHIR et al., 2013).

Devido seu alto grau poluidor, o gerenciamento inadequado desse subproduto pode causar impactos negativos ao meio ambiente, comprometendo a disponibilidade e qualidade do solo, das águas subterrâneas e superficiais. Portanto, o tratamento correto do lixiviado torna-se imprescindível, de modo que possam ser atendidas as normas vigentes antes de ser lançado nos corpos d'água (DIAS, 2017).

De acordo com Renou et al. (2008), o tratamento do lixiviado de aterro sanitário pode ocorrer por meio de processos físicos, químicos e biológicos, ou até mesmo a combinação destes. Neste contexto, os processos físicos e químicos são utilizados no pré-tratamento, em geral, para remoção das elevadas concentrações de nitrogênio amoniacal, e no pós-tratamento, para remoção de compostos recalcitrantes (AMORIM, et al., 2009). Entre as diversas alternativas de tratamento físico-químico, destaca-se a tecnologia de dessorção de amônia, que consiste no arraste de gás amônia $\left(\mathrm{NH}_{3}\right)$, geralmente utilizando torre de dessorção (DELDUQUE, 2017).

O tratamento combinado tem como objetivo a diluição do lixiviado de aterro sanitário possibilitando o seu tratamento biológico, o mesmo é preferencialmente aplicado em virtude do baixo custo e facilidade de operação (OLIVEIRA et al., 2015). Sistemas anaeróbios, como os reatores anaeróbios de fluxo ascendente (UASB), são amplamente difundidos no tratamento de esgoto doméstico e podem ser aplicados no tratamento de lixiviados com o objetivo de remoção de matéria orgânica carbonácea (ABDELGADIR et al., 2014).

Desse modo, dentre os diversos tipos de efluentes que podem ser utilizados no tratamento conjugado, tem-se a vinhaça de cana de açúcar, subproduto das destilarias de álcool. A vinhaça é um resíduo de coloração escura e é constituida principalmente por matéria orgânica e nutrientes, sua composição pode variar dependendo da matéria-prima utilizada (cana de açúcar, beterraba, 
milho, etc) (BARROS, 2017). A vinhaça de cana de açúcar comumente apresenta baixas concentrações de nitrogênio e fósforo (CHRISTOFOLETTI et al., 2013).

Tendo em vista a importância da busca por novas tecnologias de tratamento para o lixiviado gerado em aterros sanitários, como por exemplo, a utilização do tratamento conjugado utilizando a vinhaça de cana de açúcar e assumindo, desse modo, uma contribuição científica de caráter acadêmico, bem como um aporte para minimização de impactos ambientais, causado pelo lixiviado de aterro sanitário, nesta pesquisa foi avaliada a eficiência do tratamento conjugado de lixiviado de aterro sanitário e vinhaça de cana de açúcar empregando-se os processos físicos, químicos e biológicos.

\section{PROCEDIMENTOS METODOLÓGICOS}

O sistema experimental foi construído, instalado e monitorado nas dependências físicas da Estação Experimental de Tratamentos Biológicos de Esgotos Sanitários (EXTRABES), instituição da Universidade Estadual da Paraíba (UEPB), situada geograficamente no bairro do Tambor na cidade de Campina Grande, estado da Paraíba, nordeste do Brasil.

O lixiviado utilizado para a preparação do substrato é proveniente do Aterro Sanitário de cidade de João Pessoa, localizado nas coordenadas geográficas 7¹3'07’S, 3457'32”W, o qual possui uma área de 100 hectares, funcionando desde agosto de 2003, este aterro foi projetado para uma vida útil de 25 anos, tendo capacidade de confinamento de 3.000 toneladas de resíduos por dia. A vinhaça utilizada para preparação do substrato foi coletada no Engenho Triunfo, localizado na Rodovia PB-079, via de acesso à cidade de Areia, situado geograficamente nas coordenadas 658'26”S, 3541'37'W. Após a coleta ambos efluentes foram submetidos a caratezação química.

O substrato utilizado na alimentação do Reator UASB consiste da mistura de vinhaça de cana de açúcar mais lixiviado de aterro sanitário pós dessorção (\%v/v), de modo que a concentração média de nitrogênio amoniacal fosse de aproximadamente $160 \mathrm{mg} \cdot \mathrm{L}^{-1}$. As

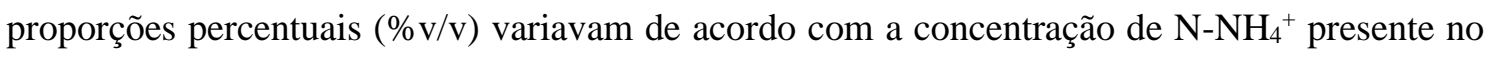
LAS após o processo de dessorção, alcançando proporções de até $80 \%$ de VCA e $20 \%$ de LAS.

O sistema experimental foi constituído por um reator de dessorção e um reator UASB, conforme apresentado na Figura 1. 
Figura 1. Desenho esquemático do sistema experimental.

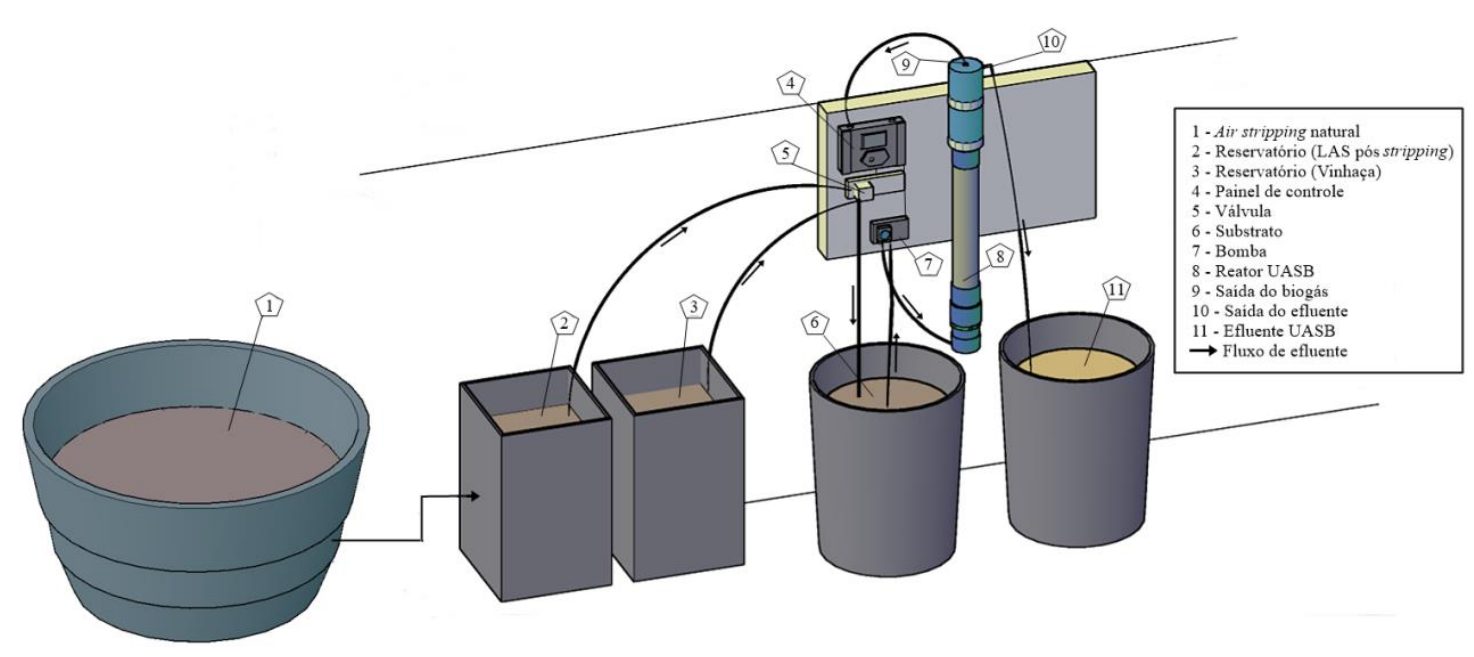

Fonte: Autor, 2022.

Observando a Figura 1, verifica-se que inicialmente o lixiviado foi disposto em um reator de dessorção (1). Após o processo de dessorção o efluente do reator é acondicionado em um novo reservatório (2). O lixiviado pós dessorção (2) e a vinhaça de cana de açúcar (3) são bombeados para preparação do substrato, este sendo submetido à agitação constante (6), em seguida o substrato é bombeado do reservatório para o reator UABS (8). Saída do efluente do UASB (10).

O início da operação do sistema experimental ocorreu com o processo de dessorção de amônia no reator 1, para alcançar uma concentração de nitrogênio amoniacal que viabilizasse a realização da mistura entre os efluentes (VCA+LAS). A carga superficial aplicada de $\mathrm{N}^{-\mathrm{NH}_{4}}{ }^{+}$no reator de dessorção foi 107,55 $\mathrm{KgNH}_{4}{ }^{+} /$ha.d com THD de 84 dias.

Em seguida ocorreu a inoculação do reator UASB com 1L de lodo proveniente de um reator anaeróbio que tratava esgoto doméstico e lixiviado de aterro sanitário, com relação de SSV/SST igual a 0,69 , sendo preenchidos $20 \%$ do volume total do reator.

No reator UASB, foi aplicado uma COV de $1,5 \mathrm{kgDQO} \cdot \mathrm{m}^{-3} \cdot \mathrm{d}^{-1}$, carga hidráulica volumétrica de $3 \mathrm{~m}^{3} \cdot \mathrm{m}^{-3} \cdot \mathrm{d}^{-1}$ e TDH de 8 horas.

O monitoramento do sistema experimental foi realizado através da coleta de amostras do efluente do processo de dessorção de amônia, do substrato e efluente UASB. Foram realizadas semanalmente analises de $\mathrm{pH}$, alcalinidade total, ácidos graxos voláteis, nitrogênio amoniacal e demanda química de oxigênio. As análises foram realizadas em consonância com os métodos preconizados por APHA (2012). 


\section{RESULTADOS E DISCUSSÃO}

Na Tabela 1 são apresentados os dados dos parâmetros advindos da caracterização química do lixiviado de aterro sanitário (LAS) e vinhaça de cana de açúcar (VCA), utilizados para a preparação do substrato.

Tabela 1. Dados provenientes da caracterização química do lixiviado de aterro sanitário (in natura), da vinhaça de cana de açúcar.

\begin{tabular}{|c|c|c|}
\hline PARÂMETRO & $\begin{array}{c}\text { LAS } \\
\text { (in natura) }\end{array}$ & VCA \\
\hline pH & 8,19 & 4,25 \\
\hline $\mathrm{AT}\left(\mathrm{mg}_{\mathrm{CaCO3}} \mathbf{L}^{-1}\right)$ & 13935,00 & - \\
\hline $\operatorname{AGV}\left(\mathbf{m g H}_{\mathrm{Ac} \cdot} \mathbf{L}^{-1}\right)$ & 9559,73 & 1020,00 \\
\hline DQO total $\left(\mathrm{mgO2} \cdot \mathrm{L}^{-1}\right)$ & 11411,7 & 5019,21 \\
\hline DQO solúvel $\left(\mathrm{mgO}^{2} \mathrm{~L}^{-1}\right)$ & 5577,59 & 3605,01 \\
\hline $\mathrm{NH}_{4}^{+}\left(\mathbf{m g} . \mathbf{L}^{-1}\right)$ & 2115,40 & 42,00 \\
\hline NTK (mg.L $\left.\mathbf{L}^{-1}\right)$ & 2688,00 & 160,16 \\
\hline SST (mg.L $\left.\mathbf{L}^{-1}\right)$ & 21120,00 & 1968,00 \\
\hline $\operatorname{SSV}\left(\mathbf{m g} \cdot \mathbf{L}^{-1}\right)$ & 786,67 & 660,00 \\
\hline
\end{tabular}

Fonte: Autor, 2022.

Após a caraterização química dos resíduos líquidos, verificou-se que ambos apresentam características que dificultariam seu tratamento por via biológica, em relação à vinhaça de cana de açúcar observa-se uma faixa de $\mathrm{pH}$ baixa para o desenvolvimento de arqueas metanogênicas.

De acordo com Chernicharo (2007) fatores como $\mathrm{pH}$ e elevadas concentrações de $\mathrm{NH}_{4}{ }^{+}$ afetam no desenvolvimento das arqueas metanogênicas, inviabilizando um possível tratamento biológico. $\mathrm{O}$ pH da vinhaça de cana de açúcar tende a ser ácido, entre as faixas de 3,9 à 4,5 (BETTANI et al., 2019; CHRISTOFOLETTI et al., 2013; REIS e HU, 2017). O pH do lixiviado encontra-se dentro da faixa apresentada na literatura para lixiviados com características semelhantes ao do presente trabalho, apresentando tendência a pH básico (NAVEEN et al., 2017; DIA et al., 2018; XIAO et al., 2013; BECK et al., 2010).

Diante deste cenário surge à ideia de realizar o pré-tratamento do lixiviado por dessorção de amônia objetivando a redução da concentração de nitrogênio amoniacal de forma que a porcentagem $(\% \mathrm{v} / \mathrm{v})$ de lixiviado no substrato fosse elevada e assim ocorresse o equilíbrio em relação ao pH do substrato, uma vez que, o LAS apresentava uma faixa de pH elevada.

Ainda na Tabela 1 observa-se que a concentração de DQO total da vinhaça de cana de açúcar está abaixo do preconizado na literatura. De acordo com Marques (2006), a concentração de DQO total de VCA in natura varia de 15.000 a $33.000 \mathrm{mgO}_{2} \cdot \mathrm{L}^{-1}$, entretanto a vinhaça em estudo passou por pré-tratamento em lagoa anaeróbia, localizada no próprio engenho, tendo suas 
características iniciais alteradas, apresentando uma concentração média de DQO total de 5019,21 $\mathrm{mgO} 2 . \mathrm{L}^{-1}$.

De acordo com Renou et al. (2008), valores de DQO de LAS de até 4.000 mg.L.'-1 são característicos de aterros antigos, e, entre 4.000 e 10.000 mg.L-1 de aterros intermediários, apesar de apresentar valor médio de DQO total de 11411,70 mg.L.-1, o aterro sanitário de João Pessoa se enquadra em aterros intermediários, pois durante o período de coleta ocorreram incidências de precipitações na região, que podem ter influenciado no valor da concentração de DQO total. Dantas (2021) encontrou valores menores de concentração de DQO total ao analisar o lixiviado do referido aterro sanitário.

\section{Tratamento físico-químico}

\section{Comportamento do pH e Nitrogênio Amoniacal}

A remoção de $\mathrm{NH}_{3}$ é um processo físico que ocorre através da conversão do $\mathrm{NH}_{4}{ }^{+}$, que é uma função direta da magnitude do pH (LEITE et al., 2018). Na Figura 02 observase que, à medida que ocorre a remoção de amônia os valores de pH do LAS elevaram-se, apresentando um $\mathrm{pH}$ inicial e final igual a 8,2 e 9,15, respectivamente.

Figura 02. Comportamento da variação temporal do pH e Nitrogênio amoniacal no reator de dessorção.

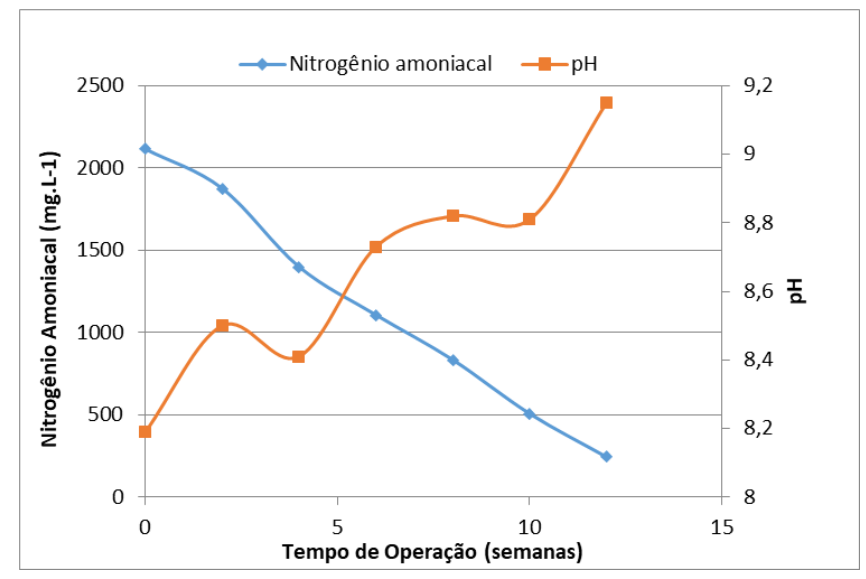

Fonte: Autor, 2022.

De acordo com Ferraz (2010) o esperado seria um decréscimo nos valores de pH e não o aumento, porém, vários autores observaram a mesma situação em experimentos com remoção de amônia do lixiviado por air stripping. Entretanto esse comportamento não foi verificado no presente estudo, haja vista ter ocorrido aumento nas magnitudes do $\mathrm{pH}$. Este aumento pode ser explicado devido ao processo de dessorção, visto que, durante o arraste do $\mathrm{NH}_{3}$ ocorre também o 
arraste de determinadas espécies químicas presentes na composição do LAS, fazendo com que haja acréscimo nos valores de pH (DUTRA, 2014).

Segundo Ferraz (2010) a remoção de amônia pode ser acompanhada pelo decréscimo da alcalinidade total, alcalinidade a bicarbonato e alcalinidade a carbonato. Portanto o equilíbrio químico do sistema carbonato poderia estar associado ao aumento do $\mathrm{pH}$. De acordo com Magalhães (2014) o comportamento do pH, neste caso, também pode ser explicado pela remoção do $\mathrm{CO}_{2}$, juntamente com a amônia. A retirada de $\mathrm{CO}_{2}$ por air stripping implicaria no consumo de íons $\mathrm{H}^{+}$e, portanto, ocasionaria o aumento do $\mathrm{pH}$ mesmo com a remoção de ammonia.

A redução da concentração de nitrogênio amoniacal em efluentes é com certeza um desafio e apresenta grande importância no tratamento de lixiviado de aterro sanitário. Analisandose o comportamento da variação temporal do nitrogênio amoniacal apresentado na (Figura 02) observa-se redução significativa na concentração de $\mathrm{N}^{-N_{4}}{ }_{4}{ }^{+}$do LAS, onde o valor inicial e final foi de 2115,4 e 243,6 mg N-NH${ }_{4}^{+} . \mathrm{L}^{-1}$, respectivamente, alcançando eficiência de $88 \%$ em 12 semanas. A temperatura foi monitorada durante o monitoramento, apresentando variações de $25^{\circ} \mathrm{C}$ à $30^{\circ} \mathrm{C}$, nenhuma mudança significativa foi notada no comportamento da temperatura ao longo das semanas, visto que, o presente estudo foi realizado no período de incidência de sol na região. O resultado obtido está em desacordo com os padrões de lançamento em corpos aquáticos, estabelecido pela Resolução CONAMA 430/2011, necessitando de um pós-tratamento.

Em trabalho realizado por Leite et al. (2018) foram alcançadas eficiências acima de 99\% no processo de remoção de nitrogênio em reatores de fluxo pistonado durante o tratamento de LAS, mostrando ser uma alternativa promissora no tratamento de lixiviado de aterro sanitário, especialmente em regiões com disponibilidade de área e temperatura ambiente acima de $25^{\circ} \mathrm{C}$.

Na Figura 03 apresenta-se a correlação estabelecida entre pH e o nitrogênio amoniacal no reator de dessorção. Observa-se que a correlação foi negativa, e que na proporção que a concentração de $\mathrm{N}-\mathrm{NH}_{4}{ }^{+}$era reduzida o $\mathrm{pH}$ aumentava. 
Figura 03. Correlação entre pH e Nitrogênio Amoniacal no LAS, durante o período de monitoramento em reator de dessorção.

Fonte: Autor, 2022.

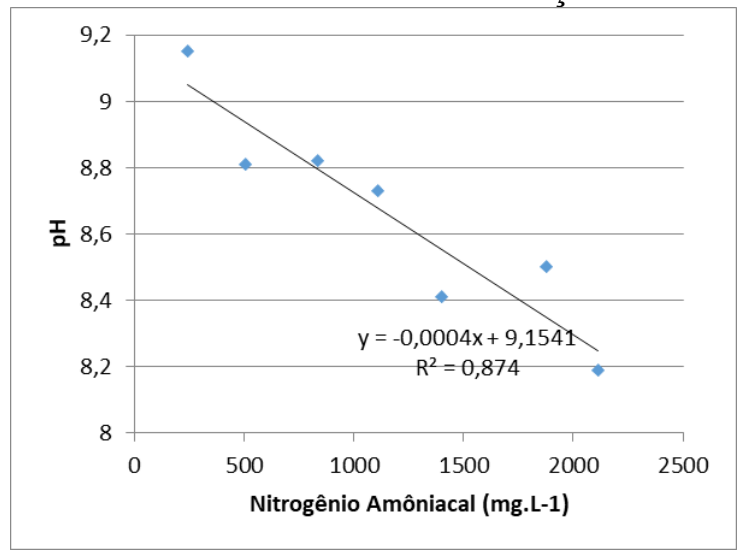

\section{Tratamento biológico}

\section{Potencial hidrogeniônico}

Analisando o comportamento dos dados apresentados na Figura 04, verifica-se que o pH do substrato variou entre 6,3 e 8,4, com valor médio de 7,3 $\pm 0,59$, apesar das variações do $\mathrm{pH}$, as condições verificadas no sistema enquadram-se na gama ótima para promover a metanogênese, entre 6,6 e 7,4, segundo Chernicharo (2007).

Com base na Figura 04, observa-se que o $\mathrm{pH}$ do efluente do reator UASB, variou de 7,6 a 8,5, com valor médio de 7,9 $\pm 0,39$ apresentando um aumento em relação ao $\mathrm{pH}$ do substrato. Esse acréscimo ocorre devido o processo de amonificação, no qual há liberação de $\mathrm{OH}^{-}$no meio. $\mathrm{O}$ aumento do $\mathrm{pH}$ pode ser justificado também, pela atividade das arqueas metanogênicas, que produzem alcalinidade na forma de dióxido de carbono, amônia e bicarbonato.

Figura 04. Comportamento do $\mathrm{pH}$ do substrato e efluente do reator UASB, durante o período de monitoramento.

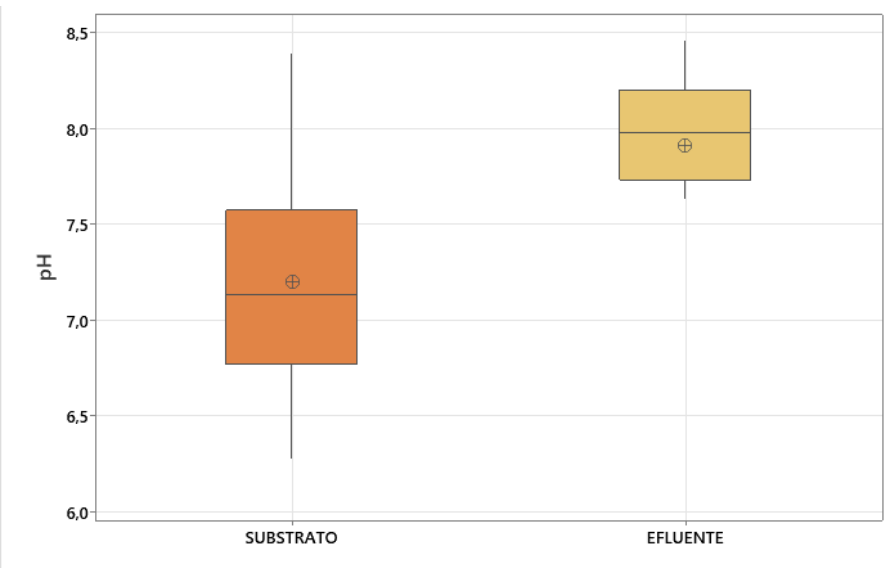

Fonte: Autor, 2022. 
De acordo com Van Handdel e Lettinga (1994) os valores de pH afetam a solubilidade e as reações de outras substâncias químicas importantes, incluindo espécies orgânicas e inorgânicas. Este se estabelece no reator após o equilíbrio iônico dos diferentes sistemas ácido/base presente em sistema de tratamento. Os sistemas de ácidos fracos, em especial os sistema carbônico, são os mais importantes para estabelecer o $\mathrm{pH}$.

A literatura mostra que a utilização de alcalinizantes químicos e/ou técnicas de recirculação do efluente são adotas para o aumento do $\mathrm{pH}$ e da capacidade de tamponamento do processo (BARROS; DUDA; OLIVEIRA, 2016; JANKE et al., 2016a; VAN HAANDEL et al., 2014). O emprego dessas técnicas poderia trazer maior estabilidade ao sistema, apesar de ter ocorrido a correção natural do pH do substrato com a mistura (VCA+LAS).

Resultados similares aos obtidos nesta pesquisa foram também verificados em estudos realizados por Oliveira et al (2015) ao analisarem o tratamento conjugado de lixiviado e esgoto doméstico em um reator UASB de $42 \mathrm{~L}$.

\section{Alcalinidade Total}

Analisando o comportamento da Alcalinidade Total no substrato, Figura 05, pode-se verificar que houve variação de 931,25 a $1641,25 \mathrm{mgCaCO}_{3} \cdot \mathrm{L}^{-1}$, apresentando concentração média correspondente a $1488,12 \pm 253,44 \mathrm{mgCaCO}_{3} \cdot \mathrm{L}^{-1}$. A digestão anaeróbia de substratos complexos resulta na produção de ácidos intermediários, sendo importante que a alcalinidade seja suficiente para manter o $\mathrm{pH}$ estável e evitar interferências nos processos metabólicos dos microrganismos (LETTINGA, 1999).

Figura 05. Comportamento da Alcalinidade Total do substrato e efluente do reator UASB, durante o período de monitoramento.

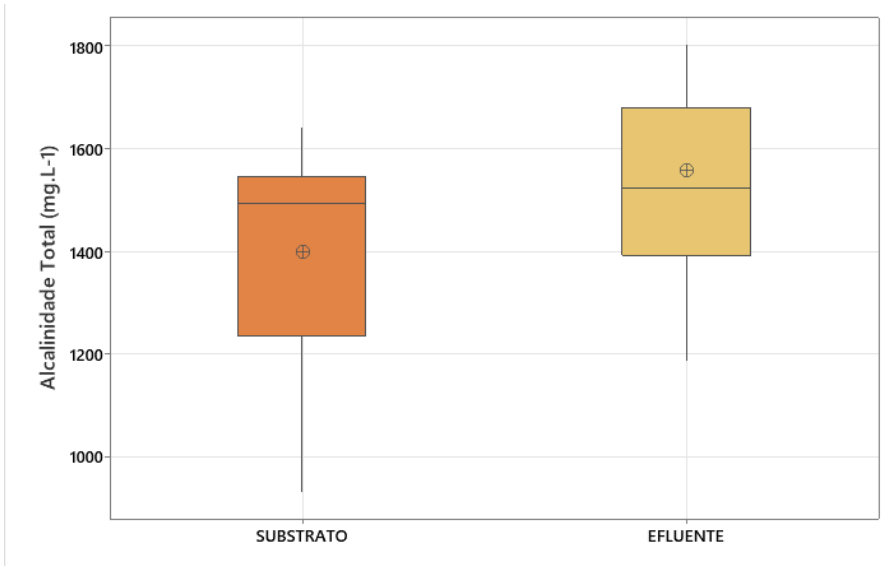

Fonte: Autor, 2022.

De acordo com os dados apresentados na Figura 05, observa-se que no efluente do reator UASB houve o aumento da concentração média de alcalinidade total, evidenciando a capacidade 
de tamponamento do reator UASB. O processo anaeróbio proporcionou o aumento de 36,25 $\mathrm{mgCaCO}_{3} \cdot \mathrm{L}^{-1}$, atingindo uma concentração média de $1524,37 \pm 247,64 \mathrm{mgCaCO}_{3} \cdot \mathrm{L}^{-1}$ no efluente do reator UASB. Esse acréscimo no valor da alcalinidade se deve principalmente ao consumo de ácidos graxos voláteis (AGV) e às reações de amonificação, nos quais a quebra de compostos orgânicos nitrogenados provoca a liberação de amônia e hidroxila $\left(\mathrm{OH}^{-}\right)$(VAN HAANDEL E LETTINGA, 1994).

\section{Ácidos Graxos Voláteis}

Analisando os dados da Figura 06, observa-se que a concentração média de AGV no substrato foi de $981,04 \pm 444,05 \mathrm{mgH} \mathrm{Ac}_{\mathrm{A}} \mathrm{L}^{-1}$, variando de 588,41 a $1343,53 \mathrm{mgH}_{\mathrm{Ac}} . \mathrm{L}^{-1}$. No efluente do reator UASB, verifica-se um decréscimo na concentração de $\mathrm{AGV}$, com valor médio de $597,26 \pm 123,97 \mathrm{mgH}_{\mathrm{Ac}} \cdot \mathrm{L}^{-1}$, este decaimento ocorre devido à assimilação dos ácidos graxos voláteis, durante o processo anaeróbio, realizado pelas metanogênicas (VAN HAANDEL E LETTINGA, 1994).

Figura 06. Comportamento dos ácidos graxos voláteis do substrato e efluente do reator UASB, durante o período de monitoramento.

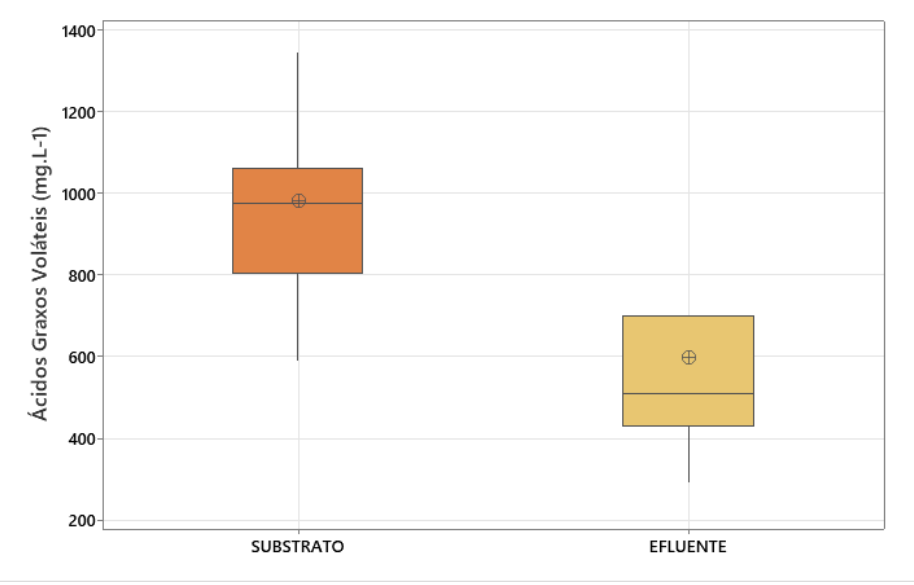

Fonte: Autor, 2022.

A relação AGV/AT pode ser utilizada como uma medida da estabilidade do processo anaeróbio (RAPOSO et al., 2009). Segundo Luque et al. (2013), quando essa relação é maior que 0,3 sugere a presença de distúrbios no processo de digestão. No efluente do reator UASB observase que a relação AGV/AT foi de 0,3 , indicando que presença de distúrbios durante o processo, a alcalinidade estava trabalhando no limite para neutralizar os ácidos formados, e tamponar o meio evitando a acidificação do reator, o que comprometeria seu desempenho.

Dantas (2021) ao analisar o tratamento conjugado de lixiviado e esgoto doméstico em um reator UASB seguido de FBP e reator anóxico, obteve relação de AGV/AT nas duas fases do seu estudo de 0,09 e 0,13 , respectivamente, durante a operação do reator UASB, evidenciando que 
havia alcalinidade suficiente no sistema para neutralizar os ácidos formados, durante o processo anaeróbio.

\section{Demanda Química de Oxigênio}

Analisando os dados na Figura 07 (a), observa-se que as concentrações de DQO total no substrato variaram numa faixa de 2923 a $5860 \mathrm{mgO} 2 \mathrm{~L}^{-1}$ no decorrer do tempo de operação, obtendo concentração média de $4273 \pm 1568 \mathrm{mgO} \cdot \mathrm{L}^{-1}$. No efluente do reator UASB, a concentração média de DQO total foi de $2452 \pm 1035 \mathrm{mgO} 2 . \mathrm{L}^{-1}$, atingindo eficiência de remoção de até $68 \%$ com proporção volumétrica de LAS e VCA de $20 \%$ e $80 \%$, respectivamente. Observase que em alguns pontos a eficiência do sistema foi relativamente baixa, esses valores podem estar associados a problemas no monitoramento, relacionados à obstrução das tubulações de alimentação do sistema, comprometendo a estabilidade do mesmo.

Figura 07. Comportamento da (a) DQO total e (b) solúvel do substrato e efluente do reator UASB, durante o período de monitoramento.

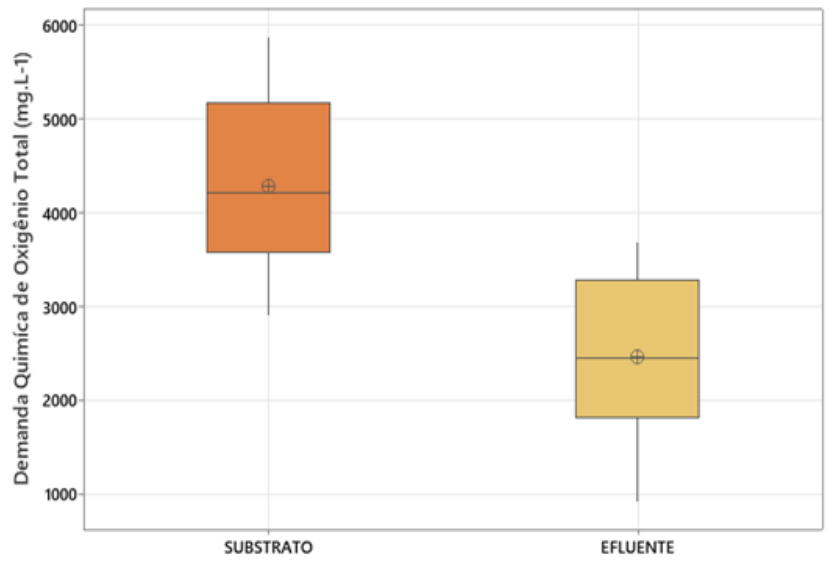

(a)

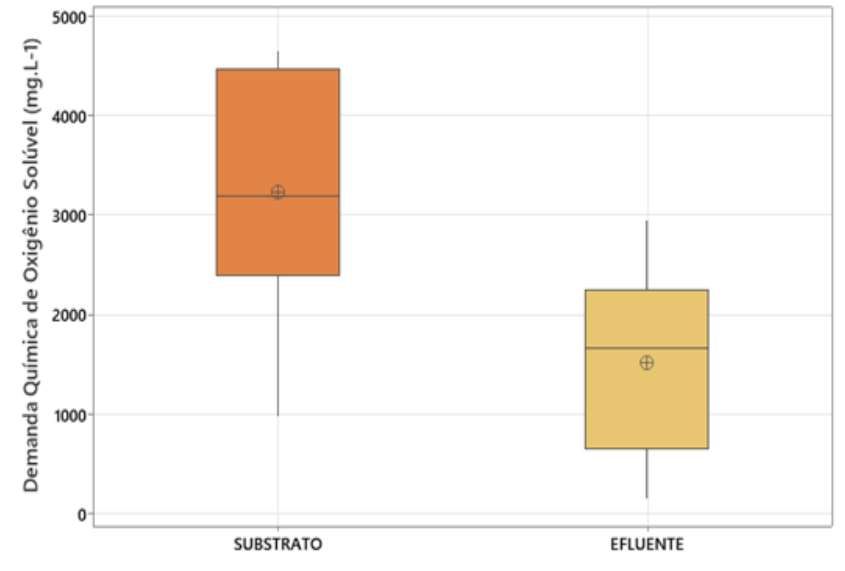

(b)

Fonte: Autor, 2022.

Entretanto, a literatura mostra eficiências acima do obtido no presente trabalho, ao se tratar lixiviado de aterro sanitário em conjunto com esgoto doméstico, porém com proporções inferiores de lixiviado no substrato. Baettker et al. (2017), operando um reator UASB tratando LAS e ED com proporções volumétricas de 5\% e 95\%, respectivamente, alcançaram eficiência de remoção de DQO de 51\%. Monteiro et al. (2019), obteve uma remoção de 48\% de DQO tratando lixiviado e esgoto doméstico em reator UASB, com proporção volumétrica de LAS de $5 \%$.

Analisando os dados da Figura 07 (b), observa-se que o substrato e o efluente do reator UASB apresentaram concentração média de DQO solúvel de $3232 \pm 1163$ mgO2.L $\mathrm{L}^{-1}$ e $1509 \pm 862$ 
$\mathrm{mgO} 2 . \mathrm{L}^{-1}$, respectivamente. O reator UASB apresentou bons resultados, alcançando a remoção média de $47,6 \%$ da DQO afluente.

\section{Nitrogênio Amoniacal}

Analisando os dados da Figura 08 observa-se que a concentração média de nitrogênio amoniacal no substrato foi de $160,7 \pm 13,01 \mathrm{mg} \mathrm{N}-\mathrm{NH}_{4}{ }^{+} . \mathrm{L}^{-1}$. No efluente do reator UASB observase um aumento na concentração média de nitrogênio amoniacal, que pode ser atribuído à ocorrência do processo de amonificação, de acordo com Metcalf e Eddy (2003) esse comportamento está associado à produção de íons hidroxila $\left(\mathrm{OH}^{-}\right)$liberados durante a conversão do nitrogênio orgânico a nitrogênio amoniacal. O efluente apresentou concentração média corresponde a $181,91 \pm 22,43 \mathrm{mg} \mathrm{N}-\mathrm{NH}_{4}+. \mathrm{L}^{-1}$.

Figura 08. Concentrações de nitrogênio amoniacal, do substrato e efluente do reator UASB, durante o período de monitoramento.

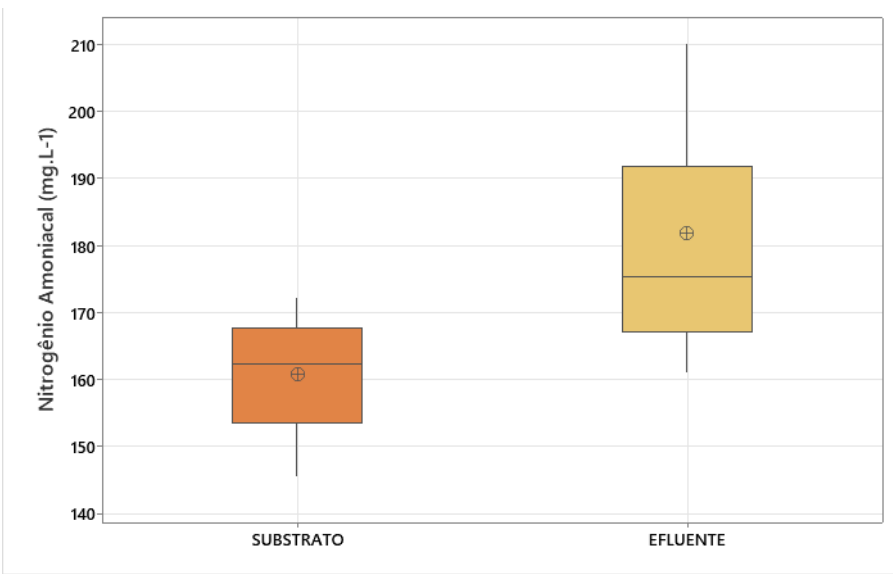

Fonte: Autor, 2022.

Comportamento semelhante foi observado por Oliveira et al. (2015) tratando LAS e esgoto doméstico com concentração média inicial e final de $60 \mathrm{mg} \mathrm{N}-\mathrm{NH}_{4}{ }^{+} \cdot \mathrm{L}^{-1}$ e $67,3 \mathrm{mg} \mathrm{N}$ $\mathrm{NH}_{4}{ }^{+} . \mathrm{L}^{-1}$, respectivamente. Araújo (2019), também constatou aumento na concentração de nitrogênio amoniacal em seu estudo, tratando LAS e esgoto doméstico em um reator UABS com capacidade de $42 \mathrm{~L}$, apresentando concentração média inicial de $153,8 \mathrm{mg} \mathrm{N}-\mathrm{NH}_{4}{ }^{+} . \mathrm{L}^{-1}$ e final de $165,6 \mathrm{mg} \mathrm{N}-\mathrm{NH}_{4}{ }^{+} . \mathrm{L}^{-1}$.

\section{CONSIDERAÇÕES FINAIS}

A dessorção de amônia do lixiviado de aterro sanitário in natura em reator de dessorção, com pH inicial de 8,19 e TDH de 12 semanas alcançou eficiência de remoção de $\mathrm{N}_{-} \mathrm{NH}_{4}{ }^{+}$de $88 \%$, sem necessidade de adição de substâncias químicas, tornando possível seu pós-tratamento por via biológica. 
O processo de dessorção de amônia do lixiviado do aterro sanitário dispensa a adição de bases alcalinas para aumentar o $\mathrm{pH}$. O processo também distribui energia para o arrasto do gás amônia, tornando-o relativamente barato quando em comparação com outros processos de remoção de amônia, especialmente o processos realizados em torres de recheio.

O tratamento conjugado de lixiviado de aterro sanitário e vinhaça de cana de açúcar em reator UASB apresentou interferências na estabilidade operacional do reator. O tratamento biológico possibilitou eficiência media de remoção de $68 \%$ e 47,6\% de material carbonáceo em termos de DQO total e solúvel, respectivamente.

O sistema apresentou relação AGV/AT igual a 0,3, indicando presença de distúrbios durante o processo, esse valor pode estar relacionado ao baixo desempenho na remoção de DQO em algumas semanas durante o monitoramento do sistema.

O TDH utilizado além de outras características como a alcalinidade e a elevada concentração de AGV na vinhaça, interferiram no desempenho do reator UASB, por se tratar de efluentes complexos, outros mecanismos, como, maior TDH, recirculação do efluente do reator UASB e adição de alcalinizantes, poderiam ser empregados para maior estabilidade do sistema e eficiência.

\section{REFERÊNCIAS}

ABDELGADIR, A.; CHEN, X.; LIU, J.; XIE, X.; ZHANG, J.; ZHANG, K.; WANG, H.; LIU, N. Characteristics, process parameters, and inner components of anaerobic bioreactors. Biomed Research International, v. 2014, 10 p., 2014.

AMORIM, A. K. B.; LANGE, L. C.; JUCÁ, J. F. T.; MOREIRA, F. A.; MORAVIA, W. G.; MORETTO, M. R. D.; SILVA, F. M. S.; LINS, E. A. M. Tratamento Físico-químico de Lixiviados: Estudos em Escala de Bancada com Precipitação Química, Coagulação/Floculação, Adsorção com Carvão Ativado e Reagente de Fenton. In: Estudo de caracterização e tratabilidade de lixiviado de aterro sanitário para condições brasileira. Rio de Janeiro: ABES, 2009.

APHA, AWWA, WPCF. Standard Methods for the Examination of Water and Wastewater. 22 ed. Washington: American Public Health Association/American Water Works Association/ Water Environment Federation, 2012.

BAETTKER, E. C.; RIETOW, J. C.; FREITAS, D. C.; AISSE, M. M. Conservação de recursos hídricos por meio do tratamento anaeróbio combinado de lixiviado de aterros sanitários em estações de tratamento de esgotos. In: Simpósio brasileiro de recursos hídricos, 20, 2017. Anais... 2017. $8 \mathrm{p}$

BARROS, V. G. DE; DUDA, R. M.; OLIVEIRA, R. A. DE. Biomethane production from vinasse in UASB reactors inoculated with granular sludge. Brazilian Journal of Microbiology, v. 47, n. 3 , p. 1-12, 2016.

BARROS, V. G. Produção de metano de vinhaça com suplementação de torta de filtro em reatores UASB em série, mesofílicos e termofílicos: desempenho do processo e diversidade microbiana. Jaboticabal, 2017. 
BASHIR, M. J. K.; AZIZ, H. A.; AZIZ, S. Q.; AMR, S. S. A. Na overview of electro-oxidation processes performance in stabilized landfill leachate treatment. Desalination and water treatment, v. 51, p. 2170-2184, 2013.

BRASIL. Lei n ${ }^{\circ} 12.305$ de 2 de gosto de 2010. Institui a Política Nacional de Resíduos Sólidos. Brasília, DF, 2 de agosto de 2010. Disponível em:

http://www.planalto.gov.br/ccivil_03/_ato2007-2010/2010/lei/112305.htm

BRASIL. Resolução nº 430/ 2011 do CONAMA. Dispõe sobre as condições e padrões de lançamento de efluentes, complementa e altera a Resolução no 357, de 17 de março de 2005, do Conselho Nacional do Meio Ambiente-CONAMA. Brasilia-DF: CONAMA, 13 de maio de 2011.

CHERNICHARO, C. A. L. Reatores anaeróbios: Princípio do tratamento biológico de águas residuárias. v. 5, $2^{\mathrm{a}}$ edição, Belo Horizonte: Ed. UFMG, 2007. 380 p.

CHRISTOFOLETTI, C. A. et al. Sugarcane vinasse: environmental implications of its use. Waste management (New York, N.Y.), v. 33, n. 12, p. 2752-61, Dec. 2013.

DANTAS, G. D. Tratamento biológico conjugado de lixiviado de aterro sanitário e esgoto doméstico. 72 p. Dissertação (Mestrado em Ciência e Tecnologia Ambiental) - Universidade Estadual da Paraíba, Centro de Ciências e Tecnologia , 2021.

DELDUQUE, Thalita Pereira et al. Remoção da amônia por air stripping em canais corrugados helicoidais. 2017. Dissertação de Mestrado. Universidade Tecnológica Federal do Paraná.

DIAS, A. C. Lodos Ativados com Adição de Carvão Ativado no Tratamento Combinado de Lixiviado de Aterro Sanitário e Esgoto Doméstico. 71p. Dissertação (Mestrado em Engenharia Agrícola e Ambiental, Meio Ambiente). Instituto de Tecnologia. Departamento de Engenharia, Universidade Federal Rural do Rio de Janeiro, Seropédica, RJ, 2017.

DUTRA, Isabelle da Cunha. Influência da granulometria e do $\mathrm{pH}$ no processo de dessorção de amônia em torres de recheio. 2014. 86 f. Dissertação (Mestrado em Tecnologia Ambiental) Universidade Estadual da Paraíba, Campina Grande, 2014.

EL-GOHARY, F.A., KAMEL, G. Characterization and biological treatment of pre-treated landfill leachate. Ecological Engineering, v.94, p. 268-274, 2016.

FERRAZ, F. M. Recuperação da amônia liberada no processo de "air stripping" aplicado ao tratamento de lixiviado de aterro sanitário. 2010. Dissertação (Mestrado em Hidráulica e Saneamento) - Escola de Engenharia de São Carlos, Universidade de São Paulo, São Paulo, 2010.

JANKE, L. et al. Enhancing biogas production from vinasse in sugarcane biorefineries: Effects of urea and trace elements supplementation on process performance and stability. Bioresource Technology, v. 217, p. 10-20, 2016a.

LEITE, V. D., PAREDES, J. M., DE SOUSA, T. A., LOPES, W. S., \& DE SOUSA, J. T. (2018). Ammoniacal Nitrogen Stripping From Landfill Leachate at Open Horizontal Flow Reactors: Leite et al. Water Environment Research, 90(5), 387-394.

LETTINGA, G. Lecture Notes Biological Wastewater Treatment Part I: Anaerobic Wasterwater Treatment.Wageningen University. 1999.

LUQUE, J.; MENDEZ, A.; RODRIGUEZ, T. Evaluación de un reactor anaerobio de flujo ascendente y manto de lodos tratando aguas residuales hospitalarias, Bogotá, Universidad Militar Nueva Granada, 2013. 
MAGALHÃES, N. C. Remoção e recuperação de amônia de lixiviado de aterro sanitário utilizando membranas contactoras e comparação com processos convencionais.130 f. 2014. Dissertação (mestrado) - Universidade Federal de Minas Gerais, Escola de Engenharia.

METCALF e EDDY. Wastewater engineering treatment Disposal Reuse. 4. ed. New York, McGraw - Hill Book, 1815p. 2003.

MONTEIRO, M. M.; BAETTKER, E.C.; AISSE, M. M.; CUBAS, S. A. Avaliação de sistema reator UASB seguido de filtro biológico percolador aplicado na codisposição de lixiviado de aterro sanitário com esgoto doméstico. In: Anais do $30^{\circ}$ Congresso Brasileiro de Engenharia Sanitária e Ambiental. Rio de Janeiro: ABES, 2019.

NASCENTES, A. L.; NASCIMENTO, M. M. P.; COSTA B. F.; CAMPOS, J. C.; FERREIRA, J. A. Tratamento combinado de lixiviado de aterro sanitário e esgoto doméstico: aspectos operacionais e microbiológicos. Revista TECCEN, v. 6, n. 1, p. 05-12, 2015.

OLIVEIRA, E. G.; LEITE, V. D.; SILVA, R. B.; HENRIQUE, I. N.; BARROS, A. J. M. Tratamento anaeróbio e aeróbio de lixiviado de aterro sanitário. Revista AIDIS, Vol. 8, No. 3, $360-371,2015$.

RAPOSO, F..; BORJA, F..; MARTÍN, M..; RINCON, B. Influence of inoculum-substrate ratio on the anaerobic digestion of sunflower oil cake in batch mode: Process stability and kinetic evaluation. Chemical Engineering Journal, v. 149, p. 70-77, 2009.

RENOU, S.; GIVAUDAN, J. G.; POULAIN, S.; DIRASSOUYAN, F.; MOULIN, P. Landfill leachate treatment: Review and opportunity. Journal of Hazardous Materials, n. 150, p. 468493, 2008.

VAN HAANDEL, A. C., LETTINGA, G. Tratamento Anaeróbio de Esgotos: Um Manual para Regiões de Clima Quente. Campina Grande: Epgraf, 240p., 1994.

VAN HAANDEL, A. et al. Methanosaeta dominate acetoclastic methanogenesis during highrate methane production in anaerobic reactors treating distillery wastewaters. Journal of

Chemical Technology and Biotechnology, v. 89, n. 11, p. 1751-1759, 2014. 